Motrivivência Ano XXI, No 32/33, P. 178-192 Jun-Dez./2009

\title{
CONSIDERAÇÕES SOCIAIS E SIMBÓLICAS SOBRE SEDES DE MEGAEVENTOS ESPORTIVOS
}

\author{
Bórbara Schausteck de Almeida' \\ Fernando Marinho Mezzadri \\ Wanderley Marchi Júnior ${ }^{3}$
}

\begin{abstract}
Resumo Abstract
O processo de transformação do esporte tem tornado as competições internacionais em megaeventos, com relação ao alcance mundial e as estruturas físicas e financeiras necessárias. Nesse contexto, tendo o Brasil papel chave na conjuntura
\end{abstract}

1 Bacharel (2007) e mestre (2010) em Educação Física pela Universidade Federal do Paraná, na linha de pesquisa Sociologia do Esporte e Lazer. É membro do Centro de Pesquisa em Esporte, Lazer e Sociedade (CEPELS) e da Asociación Latinoamericana de Estudios Socioculturales del Deporte (ALESDE). Contato: barbara.edf@ufpr.br

2 Doutor em Educação Física pela Universidade Federal de Campinas (2000). É vice-diretor do Setor de Ciências Biológicas da Universidade Federal do Paraná, onde também atua como professor adjunto da graduação e pós-graduação em Educação Física e na coordenação do núcleo UFPR da Rede CEDES/Ministério do Esporte. Membro do Centro de Pesquisa em Esporte, Lazer e Sociedade (CEPELS) e da Asociación Latinoamericana de Estudios Socioculturales del Deporte (ALESDE). Contato: mezzadri@ufpr.br

3 Doutor em Educação Física pela Universidade Federal de Campinas (2001). É professor efetivo do programa de pós-graduação (mestrado e doutorado) em Educação Física e em Ciências Sociais da Universidade Federal do Paraná (UFPR). Coordena o Centro de Pesquisa em Esporte, Lazer e Sociedade (CEPELS) e o grupo de pesquisa Deporte y Esparcimiento da Associação Latino-americana de Sociologia (ALAS). É vice-presidente da Asociación Latinoamericana de Estudios Socioculturales del Deporte (ALESDE).Contato: marchijr@ufpr.br 
Ano XXI, n 32/33, junho e dezembro/2009

global recente, realizamos uma revisão de literatura visando compreender as possíveis vantagens e intenções políticas na promoção desses eventos, com base na teoria sociológica de Pierre Bourdieu.

Como resultados, destacamos que os megaeventos têm sido promovidos com intenções sociais e simbólicas baseadas

em experiências bem sucedidas anteriores de criação e/ou divulgação da imagem de países/cidades.

Palavras-chave: Campo Esportivo; Megaeventos; Campo Político.

\section{Introdução}

Desde 2007 até 2016, o Brasil vem aumentando e tende a aumentar exponencialmente sua evidência como cenário de grandes eventos esportivos. Após sediar os XV Jogos Pan e Parapan-Americanos no Rio de Janeiro em 2007 (Rio 2007), o país sediará os $5^{\circ}$ Jogos Mundiais Militares em 2011 (Rio 2011), a Copa das Confederações em 2013, a Copa do Mundo de futebol em 2014 e os Jogos Olímpicos e Paraolímpicos de 2016 (Rio 2016).

Dentro de uma leitura crítica desse contexto que se estabelece, o primeiro ponto é compreender o que se entende por megaeventos. Ainda que em algumas publicações, considerem todos os eventos listados como "megaeventos", outros membros da comunidade acadêmica in- developed a bibliographic review in order to understand the advantages of political intentions in promoting these events based on Pierre Bourdieu's sociological theory. As main results, we highlight that mega-events are being promoted with social and symbolic intentions based on past well-succeed experiences of creating and/or promoting a global city/country images.

Key-words: Sporting Field; Mega-events; Political Field.

ternacional (DACOSTA, 2002; MALFAS; THEODORAKI; HOULIHAN, 2004; HORNE; MANZENREITER, 2006; DUNCAN, 2007; HORNE, 2007; WHANNEL, 2009; GIULIANOTTI; KLAUSER, 2010) seguem as construções teóricas de Maurice Roche (2000), que considera:

Megaeventos são eventos de larga escala cultural (incluindo comerciais e esportivos) que tem uma característica dramática, apelo popular massivo e significância internacional. Eles são tipicamente organizados por combinações variáveis de governos nacionais e organizações internacionais não governamentais e ainda podem ser ditos como importantes elementos nas versões "oficiais" da cultura pública. (ROCHE, 2001, p.1, tradução nossa). 
Na intenção de diferenciar os eventos públicos conforme seu tipo e dimensão, Roche (2001) criou uma tabela a partir de outros estudos visando um meio de classificação dos eventos através de seu alcance de mídia e mercado.

Sob essas perspectivas, os eventos a serem realizados no Brasil podem ser caracterizados da seguinte forma: os Jogos Olímpicos e a Copa do Mundo possuem mercado e mídia globais, considerados por isso megaeventos; os Jogos Militares tem impacto de público internacional em menor proporção, com maior ênfase da mídia nacional; e os Jogos Pan-Americanos têm impacto de mídia internacional em menor proporção, porém com público regional.

Ou seja, num intervalo de dez anos, o país sediará sete grandes eventos esportivos, sendo somente dois considerados megaeventos: a Copa do Mundo e os Jogos Olímpicos e Paraolímpicos.

Esse esclarecimento tornase necessário para contextualizar os diferentes interesses que têm sido delineados pelos agentes envolvidos na organização e promoção dos eventos: as instituições esportivas, iniciativa privada e entes governamentais. De forma paralela, isso não retira os méritos da demonstração da capacidade organizacional e de financiamento desses agentes para sediar os eventos, assim como não os exime da responsabilidade em sua execução ideal.

Sob a égide do conceito "megaeventos", ainda que os eventos esportivos pareçam os únicos que possuem esse perfil, outros tipos também são considerados como as Expos Mundiais (ROCHE, 2000; VRIJALDENHOVEN, 2007), organizadas pelo Bureau International des Expositions (BIE) ${ }^{4}$.

]Uma amostra da semeIhança de características entre esses eventos e os esportivos pode ser vista na exposição de António Firmino da Costa (2002), quando se referia à Expo de 1998 em Lisboa e ao "paradoxo das identidades culturais em contexto de globalização":

Porventura, um dos aspectos mais importantes a sublinhar é, justamente, o cruzamento de dinâmicas identitárias que este tipo de contexto urbano cosmopolita proporciona. Cruzamento que se estabeleceu entre cada

4 A edição de 2010, realizada em Shanghai, China, com duração de seis meses (de 01 de maio até 31 de outubro), tem como tema "Better City, Better World" ("Cidade melhor, mundo melhor" na tradução livre) e a expectativa de receber 70 milhões de visitantes (EXPO 2010 SHANGHAI CHINA, 2010). 
Ano XXI, n 32/33, junho e dezembro/2009

uma das representações de identidade cultural nacional ali presentes e a representação de uma "síntese global" da multiplicidade cultural planetária; síntese global essa, por sua vez, "localizada" num espaço de representação que se constituiu como referente identitário privilegiado da cidade e da sociedade promotoras. (COSTA, 2002, p. 23)

Na descrição resultante da investigação dos aspectos culturais e identitários presentes naquele evento, Costa (2002) indica uma contribuição sob o ponto de vista sociológico para a análise de megaeventos que provavelmente em muito se aproxima aos eventos esportivos que presenciaremos nos próximos anos. Por essa abordagem, a aproximação nas características dos megaeventos não é restrita ao alcance mundial e a quantidade de espectadores, como sugere Roche (2000), mas também sua constituição como campo fértil de investigação de relações sociais complexas e paradoxais da sociedade moderna.

A riqueza de possibilidades de investigação sobre os megaeventos abrange inúmeras áreas de conhecimento necessárias para sua produção e análise: a Geografia e a Engenharia de Transportes sobre as reestruturações urbanas (MASCARENHAS, 2004; MYIAMOTO, 2006; BORGES,
2009; COSTA, 2009; GAFFNEY, 2010), a Engenharia de Produção e a Economia, com ferramentas para análise de impactos (BARROS, CONSENZA, 2007; PRONI, ARAÚJO, AMORIM, 2008), além da Educação Física e Comunicação, com observação de fatores como turismo (REIS, 2004), mídia (FORTUNA, 2009), gestão de segurança (SILVA, 2005) e gestão de legados (VILLANO, 2009), são algumas pesquisas nacionais realizadas, em sua maioria, em decorrência do Rio 2007.

Outras produções da área que se destacam estão presentes em dois livros, resultantes de seminários organizados no país: "Legados de Megaeventos Esportivos" (DACOSTA et al., 2008); e "Megaeventos esportivos, legado e responsabilidade social" (RUBIO, 2007). As duas obras trazem colaborações de diferentes facetas, discussão e análise de ferramentas sobre legados, estudos de caso de edições passadas de Jogos Olímpicos e outros megaeventos realizados no país, entre outros temas.

Ainda no campo acadêmico, a revista Motrivivência em 2006 dedicou uma edição sobre os grandes eventos esportivos no Brasil, em razão da realização do Rio 2007 no ano seguinte e na iminência da escolha do Brasil como sede da Copa do Mundo de 2014. Ainda que apenas uma contribuição 
abordasse diretamente a temática (CAPELA, 2006), além do editorial (SILVA; PIRES, 2006), o viés crítico parece mais sobressalente que nas produções citadas anteriormente.

Após esse breve panorama dos estudos acadêmicos no país, percebemos que a produção ainda é restrita, com esforços pontuais para o desenvolvimento dessa área de investigação inspirados pela realização do Rio 2007. Para os próximos anos, não nos faltam razões que poderão impulsionar o Brasil para uma posição de destaque também na área acadêmica dos megaeventos.

Na literatura internacional, alguns centros de investigação tornaram-se referência acadêmica após cidades e países terem sediado megaeventos esportivos, principalmente os Jogos Olímpicos de verão. Destacamse Los Angeles/Estados Unidos 1984 e Barcelona/Espanha 1992, além da recente e relevante inserção nesse cenário de Pequim/China 2008 e Londres/Inglaterra 2012.

Partindo de algumas das pesquisas citadas e de outras internacionais, pretendemos nesse estudo focar em uma abordagem que parece ter sido pouco discutida nacionalmente: as relações que os megaeventos estabelecem com a política. Dessa forma, se coloca como questão problematizadora: quais são as possíveis vantagens para o Rio de
Janeiro e o Brasil, sob o ponto de vista político e simbólico, ao hospedar megaeventos esportivos, com base em edições anteriores?

Com isso, o objetivo principal dessa pesquisa é investigar quais foram as principais vantagens apresentadas por outras cidades e países que promoveram megaeventos esportivos de acordo com casos citados na literatura científica.

Como opção teórica, optamos por utilizar parte da teoria sociológica do autor francês Pierre Bourdieu que, embora não tenha sido um sociólogo do esporte, traz relevantes abordagens e reflexões sobre o fenômeno esportivo em seu processo de profissionalização e espetacularização (BOURDIEU, 1983), inclusive quando dedicou uma reflexão sobre a televisão e os Jogos Olímpicos (BOURDIEU, 1997). Além das abordagens relacionadas ao campo esportivo, suas contribuições sobre as lógicas de funcionamento do campo político (ou burocrático) (BOURDIEU, 1998; 2003) também são construtivas para as análises aqui realizadas.

Dentre as contribuições nacionais em estudos relacionados a megaeventos, não encontramos nenhuma pesquisa que tenha abordado a temática conforme propomos aqui. Acreditamos com essa pesquisa poder trazer alguns subsídios para novas interpretações sobre 
Ano XXI, n 32/33, junho e dezembro/2009

os interesses políticos na realização de megaeventos esportivos.

A presente pesquisa caracteriza-se como de cunho qualitativo e exploratório ao pretender iniciar a discussão através "explicação do funcionamento das estruturas sociais" (RICHARDSON, 2008, p. 82) que estão relacionadas à realização de megaeventos esportivos. Como um estudo qualitativo, buscamos "a riqueza interpretativa, a contextualização do ambiente, dos detalhes e das experiências únicas" (SAMPIERI; COLLADO; LUCIO, 2006, p. 15). Por isso, classificamos esta pesquisa também como exploratória, para "examinar um tema ou problema de pesquisa pouco estudado" (SAMPIERI; COLLADO; LUCIO, 2006, p. 99).

Quanto à coleta de dados, para consecução da pesquisa foi realizada uma revisão bibliográfica em artigos a partir dos anos 2000 em periódicos internacionais que abordem a temática "megaeventos" com ênfase nos aspectos políticos para sua promoção. Alguns livros também foram úteis na presente construção ao referendar as demais discussões iniciadas através dos dados provenientes dos artigos.

\section{Resultados}

No mapeamento realizado, pudemos identificar que alguns autores dão mais ênfase do que normalmente é visto sobre os fatores de exposição da cidade em contexto mundial como um dos aspectos motivadores de candidaturas à sede de megaeventos.

Para Andranovich, Burbank e Heying (2001), que investigaram os Jogos Olímpicos de Los Angeles 1984, Atlanta 1996 e Salt Lake City 2002, publicando os resultados em dois estudos (ANDRANOVICH; BURBANK; HEYING, 2001; BURBANK; ANDRANOVICH; HEYING, 2002), as cidades se candidatam a hospedar megaeventos como uma estratégia que oportuniza: (1) exposição midiática regional, nacional e internacional a baixos custos $^{5}$; (2) o desenvolvimento de projetos em prazos definidos, onde "os Jogos Olímpicos são prestigiosos o suficiente para forçar decisões rápidas" (ANDRANOVICH; BURBANK; HEYING, 2001, p. 127) mesmo em situações ou políticas de desenvolvimento problemáticas - e aqui podemos considerar a burocracia para o caso brasileiro -, atuando como

5 A perspectiva de "baixos custos" pode ser questionada. Mas é preciso contextualizar o país dos autores, Estados Unidos, e considerar que nas informações oficiais dos casos investigados pelos autores, constam superávits no balanço final dos eventos e, de forma geral, a ausência de mudança nas taxas pagas pelos contribuintes. 
um estímulo ou justificativa para o desenvolvimento de projetos locais (BURBANK; ANDRANOVICH; HEYING, 2002); (3) e um aumento no turismo (ANDRANOVICH; BURBANK; HEYING, 2001), atraindo outros eventos, negócios ou mesmo novos residentes, elegendo os Jogos Olímpicos como uma opção estratégica de escolha das cidades para criar ou desenvolver uma imagem global (BURBANK; ANDRANOVI$\mathrm{CH}$; HEYING, 2002).

Neste último ponto, os autores consideram uma questão problemática quanto o desenvolvimento da cidade para turistas e a dificuldade de lidar com as problemáticas dos residentes.

No caso das cidades americanas, que os comitês organizadores eram compostos majoritariamente pela iniciativa privada, tal situação tornava-se menos acentuada que em outros casos. Mesmo assim, como existe dinheiro público envolvido, os interesses da população também precisam ser atendidos para além das experiências intangíveis, o que atualmente continua sendo um desafio.

Nesse ponto, eles concluem que o planejamento e a candidatura para os Jogos dependem de parcerias público-privadas com abstenção da participação dos cidadãos, sendo aspectos comuns na política urbana "por trás da retórica e simbolismo do movimento olímpi-
CO" (ANDRANOVICH; BURBANK; HEYING, 2001, p. 128).

Uma consideração dos autores que pode ser válida e apropriada para o caso brasileiro é que "ter a presença variada do setor público no planejamento de um megaevento não garante uma política mais 'pública'" (BURBANK; ANDRANOVICH; HEYING, 2002, p. 195). Dessa forma, o envolvimento da sociedade civil é fundamental para investigar e cobrar alternativas que gerem resultados para uma população mais ampla.

Ainda sobre a criação de uma imagem global, Payne (2006) desenvolve melhor essa questão:

Sediar os Jogos Olímpicos pode servir como uma das mais poderosas plataformas para qualquer país. Os governos gastam bilhões de dólares todos os anos trabalhando sua imagem no resto do mundo. Tentam influenciar o modo como são percebidos por outras nações e sabem que a imagem de uma nação afeta relacionamentos políticos e econômicos. Seja para aumentar o turismo, mudar a política interna e externa, atrair investimentos ou ajuda ou meIhorar o comércio internacional, a intenção do gerenciamento da imagem nacional é colocar a nação sob uma luz mais favorável 
Ano XXI, n 32/33, junho e dezembro/2009

para o resto do mundo. (PAYNE, 2006, p. 178-179)

Considerando que esse autor teve um grande envolvimento com o Comitê Olímpico Internacional, atuando na área de marketing, seu discurso exige cuidadosa incorporação. Entretanto, outros autores também seguem esse raciocínio, considerando não exclusivamente o turismo acerca da boa imagem que hospedar megaeventos pode proporcionar (MASCARENHAS, 2004; BLACK, 2007; PRONI, ARAUJO, AMORIM, 2008).

Black (2007) abordou a "política simbólica" presente em três cidades/países sede de grandes eventos esportivos de 2010 (Copa do Mundo de futebol na África do Sul, Commonwealth Games ${ }^{6}$ em Nova Delhi, Índia e Jogos Olímpicos de Inverno em Vancouver, Canadá). A comparação entre países de realidades políticas, sociais, econômicas e posicionamentos geográficos distintos mostrou alguns aspectos comuns, como a competição por um posicionamento global, ao mesmo tempo em que não haja perda de identidade local, e uma oportunidade de legitimação da ação política.

Glynn (2008) traz conclusões semelhantes nesse sentido ao tratar do impacto dos Jogos
Olímpicos na comunidade cívica. A busca por um status de "cidade do mundo" é, usualmente, bem sucedida de forma legítima com a associação a esse megaevento que se incorpora, intencionalmente ou não, as características da cidade após sua realização.

Na perspectiva simbólica, nos países "do sul" o envolvimento de oficiais de altos cargos para o desenvolvimento dos megaeventos é destacado em comparação com os países "do norte", já que há uma alta preocupação em não falhar na promoção desses eventos (BLACK, 2007). Apropriando ao caso brasileiro, esse é um aspecto que também tem sido observado, cuja motivação específica está aberta como possibilidade de pesquisa empírica para a comunidade acadêmica.

Também tratando da relação de países de "terceiro mundo" ou "em desenvolvimento" com os megaeventos, Hiller (2000) disserta sobre a candidatura da Cidade do Cabo, África do Sul, para os Jogos Olímpicos de 2004. Segundo o autor, a candidatura enfatizava o desenvolvimento humano como principal motivador e foco da possível realização do evento. Essa ideologia auxiliou na legitimidade para conquistar o apoio governamental.

6 Jogos da comunidade britânica, realizado a cada quatro anos com a participação de 54 países de todos os continentes. Para mais informações, ver < http://www.thecgf.com/>. 
Entre as iniciativas que confirmariam esse compromisso estava a construção dos equipamentos esportivos em áreas desprivilegiadas, como um atrativo para o desenvolvimento de outros aspectos da região e para ações de projetos esportivos, oportunidade de trabalho e qualificação de mão de obra, melhoria das condições de habitação e transporte, suporte aos pequenos negócios, com constante consulta à opinião pública. Como é comum em qualquer candidatura, o autor cita também algumas intenções da iniciativa privada.

Entretanto, a candidatura ideológica não foi bem sucedida. Segundo o autor, pela lógica elitista e comercial que os Jogos Olímpicos possuem, "enquanto os megaeventos podem ser um instrumento de desenvolvimento como consequência, eles nunca se tornaram seu escravo" (HILLER, 2000, p. 455), ou seja, mesmo para os países menos favorecidos, a realização do megaevento deve ser a prioridade e o desenvolvimento a consequência, não o inverso.

A mesma ideia é desenvolvida por Horne (2007, p. 92) quando resume que os megaeventos são uma parte significante da experiência da modernidade, mas não podem ser vistos como panaceia, como solução para os problemas sociais e econômicos.

Por esses pontos de vista, é possível concordar com Pillay e Bass (2008), que tratam sobre a Copa do Mundo de futebol na África do Sul 2010, que os megaeventos têm sido promovidos com inúmeras promessas não cumpridas de desenvolvimento e diminuição da pobreza na intenção de mobilizar a opinião pública. A dificuldade no cumprimento desses objetivos está na falta de planejamento antecipado e ausência de discussão no meio acadêmico local sobre as questões de legado efetivo.

Abordar possíveis vantagens que um megaevento proporciona para uma cidade ou país e seus cidadãos a referência feita é, inevitavelmente, a um conjunto de bens, tangíveis e intangíveis, comumente entendido sob a nomenclatura "legados".

A produção de um megaevento exige um investimento bilionário de verbas públicas de países sede cujo impacto não deve estar restrito a um curto período de realização, como duas semanas no caso dos Jogos Olímpicos ou um mês como nas Copas do Mundo de futebol. Assim, há uma busca constante por potencializar as possíveis consequências positivas dos megaeventos.

\section{Discussão}

A existência de megaeventos esportivos, tal como se constituem hoje, evidencia a passagem 
Ano XXI, n 32/33, junho e dezembro/2009

do amadorismo para o profissionalismo no Movimento Olímpico. A realização e sustentação financeira dos eventos são possibilitadas pelo forte investimento financeiro e o vislumbre de retorno proporcional das iniciativas públicas e privadas.

As elites atuais do esporte moderno visam manter sua posição no campo esportivo, na constante tentativa do estabelecer o "monopólio de imposição da definição legítima da prática esportiva e da função legítima da atividade esportiva" (BOURDIEU, 1983, p. 142). Na disputa entre agentes e instituições que tem o poder de classificar tais práticas, o COI e a FIFA são entidades que atualmente se destacam como detentoras desse monopólio.

Em se tratando de megaeventos, a percepção dessa evidência é clara quando os países e cidades têm uma vasta mobilização de recursos humanos e financeiros visando conquistas simbólicas que circundam principalmente o universo olímpico, conforme alguns dos autores pesquisados (ANDRANOVICH; BURBANK; HEYING, 2001; GLYNN, 2008; HORNE, 2007).

Os Jogos Olímpicos e a Copa do Mundo de futebol possuem a maior visibilidade midiática mundial e grande interesse do públiCo, provavelmente maior que qualquer outro evento quando se trata de exposição intensa durante todos os dias de sua realização em uma escala global. Os dirigentes esportivos e políticos ligados ao esporte têm a possibilidade de converter os aspectos simbólicos e miméticos das disputas entre os países, desde as candidaturas a sediar os Jogos até a conquista de medalhas, em capital político e social.

Bourdieu (1983) compreende que a capacidade de envolvimento e mobilização do esporte um meio potencial para a conquista política e simbólica. A maximização de sua influência, proporcionada pelo desenvolvimento e alcance dos meios de comunicação, viabiliza as principais razões apontadas como lucros das cidades-sede: criação e desenvolvimento de imagem global, exposição midiática regional, nacional e internacional de forma "espontânea", diferentemente de outros meios. Nesse sentido se evidencia a força da relação esporte, mídia e espetáculo, na qual a televisão possui um papel central.

A intensificação das transmissões televisivas gerou modificações ou reforço de algumas características observadas no esporte atual e no envolvimento dos Estados, desde as orientações nacionais para sucessos internacionais na exploração das vitórias, assim como na "planetarização do espetáculo olímpico" (BOURDIEU, 1997, p. 126). 
Porém, a utilização do esporte como meio de promoção política se dá de forma dissimulada (BOURDIEU, 1983, p. 146-7). Ainda que haja a possibilidade de conversão em capital político a partir do esporte, e no caso analisado dos megaeventos, as intenções não são necessariamente explícitas. Alguns dos lucros potenciais através dos legados são expostos e trabalhados para a mobilização da opinião pública em favor da realização dos eventos. Mas uma participação mais ativa da população, desde a realização de um levantamento e consequente discussão sobre o desejo da população de receber os jogos até de que formas os projetos devem ser trabalhados para potencializar suas vantagens, é inexistente na maioria dos casos.

Aproximando as discussões dos megaeventos ao campo político, podemos entender o esporte como um subcampo componente da chamada mão esquerda do Estado (BOURDIEU, 1998), tido muitas vezes como meio de "resolver as mazelas sociais". Por isso, é comum vermos políticas de governo que utilizam deste discurso para implantar programas sociais esportivos cujos profissionais devem "exercer as funções ditas "sociais" - isto é, compensar, sem dispor de todos os meios necessários, os efeitos e carências mais intoleráveis da lógica do mercado", exatamente como outros agentes da mão esquerda como "policiais e magistrados subalternos, assistentes sociais, educadores" (BOURDIEU, 2003, p. 218).

Mesmo o esporte de alto rendimento, incluindo aí o esporte olímpico e profissional, com suas aspirações que incluem os megaeventos, podem ser observados como estando na mão esquerda do Estado brasileiro quando, mesmo "sem dispor de todos os meios necessários", as suas conquistas internacionais são acompanhadas de discursos que enaltecem o esforço de cidadãos de uma nação, numa tentativa de resgatar o descrédito e a descrença de uma população com dificuldades múltiplas.

De forma preliminar, vê-se que o campo do esporte está numa posição dominada perante outros campos dentro do campo político. Porém, o esporte olímpico e profissional, como dominantes no campo esportivo, buscam uma posição de dominância e/ou autonomia também no metacampo do Estado.

Com esse subsídio teórico fornecido por Pierre Bourdieu, torna-se mais clara as relações que se estabelecem entre as entidades administradoras do esporte no país, notadamente COB, Confederação Brasileira de Futebol (CBF) e o Governo Federal brasileiro. Uma posição de maior destaque para as ações dessas 
Ano XXI, n 32/33, junho e dezembro/2009

instituições tem sido dada após a "conquista do direito" a sediar os megaeventos de 2014 e 2016.

\section{Considerações finais}

De acordo com a literatura científica revisada, para o país e para a cidade sede, há casos bem sucedidos de crescimento no turismo e outras formas de investimentos econômicos externos, além de uma evidência midiática global que favorece um enriquecimento de imagem frente a outros Estados.

Na recorrente perspectiva de que megaeventos proporcionam legados positivos e negativos quanto aos bens tangíveis - investimentos com retorno duradouro ao invés de altos gastos para resultados provisórios -, é unânime a necessidade de um planejamento consistente para potencializar os pontos positivos e neutralizar os negativos.

Ainda que não se perca de vista a crítica sobre a restrita participação popular e científica na preparação em longo prazo para sediar tais megaeventos, o conhecimento científico precisa se desenvolver. De modo geral pudemos observar que ainda faltam subsídios técnicos independentes dos interesses dos realizadores dos eventos para aferir os legados econômicos e sociais.

\section{REFERÊNCIAS}

ANDRANOVICH, Greg; BURBANK, Matthew J.; HEYING, Charles H.. Olympic Cities: Lessons Learned from Mega-Event Politics. Journal of Urban Affairs, v. 23, n. 2, pp. 113-131, 2001.

BARROS, Carlos Frederico O.; COSENZA Carlos Alberto N. Usando Lógica Fuzzy em Megaeventos de Esportes:um sistema de avaliação de impactos. In: ENCONTRO NACIONAL DE ENGENHARIA DE PRODUÇÃO, 27., 2007, Foz do Iguaçu. Anais eletrônicos... Rio de Janeiro: ABEPRO, 2007. Disponível em: < http://www.abepro.org. br/biblioteca/ENEGEP2007 TR680488_9882.pdf $>$. Acesso em: 26 mai. 2010.

BLACK, David. The Symbolic Politics of Sport Mega-Events: 2010 in Comparative Perspective. Politikon, v. 34, n. 3, pp. 261276, dez. 2007.

BOURDIEU, Pierre. Como se pode ser esportivo? In: Questões de Sociologia. Trad. Jeni Vaitsman. Rio de Janeiro: Marco Zero, 1983. Título original em francês: Questions de Sociologie.

. Os Jogos Olímpicos. In: Sobre a televisão. Trad. Maria Lúcia Machado. Rio de Janeiro: Jorge Zahar Editor, 1997. Título original em francês: Sur la televisión. 
Contrafogos: táticas para enfrentar a invasão neoliberal. Trad. Lucy Magalhães. Rio de Janeiro: Jorge Zahar, 1998. Título original em francês: Contre-feux: propos pour servir à la résistance contre l'invasion neo-libérale.

(Coord.). Miséria do Mundo. Trad. Mateus S. Soares Azevedo et al. Rio de Janeiro: Vozes, 2003. Título original em francês: La Misère du Monde.

BORGES, Fátima Cristina da Silva. A cidade para quem? Empreendedorismo e Resistências nos Jogos PanAmericanos do Rio de Janeiro: O caso da Marina da Glória. 155p. Dissertação (Mestrado em Geografia). Universidade do Estado do Rio de Janeiro, Rio de Janeiro, 2009.

BURBANK, Matthew J.; ANDRANOVICH, Greg; HEYING, Charles H.. MegaEvents, Urban Development and Public Policy. The Review of Policy Research, v. 19, n. 3, pp. 179-202, 2002.

CONFEF. Mega-eventos 2011/2016 - O que eles pensam. Conselho Federal de Educação Física, ano 11, n. 35, mar. 2010.

COSTA, António Firmino da. Identidades culturais urbanas em época de globalização. Revista Brasileira de Ciências Sociais, v. 17 n. 48 , fev. 2002.
COSTA, Marcela Rubert Arantes da. Estratégias para os transportes em megaeventos. Dissertação de Mestrado, Engenharia de Transportes, Universidade Federal do Rio de Janeiro, Julho de 2009.

DACOSTA, Lamartine Pereira. Olympic Studies: Current Intellectual Crossroads. Rio de Janeiro: Editora Gama Filho, 2002.

DACOSTA, Lamartine Pereira; CORRÊA, Dirce; RIZZUTTI, Elaine; VILLANO, Bernardo; MIRAGAYA, Ana. Legados de Megaeventos Esportivos. Brasília: Ministério do Esporte, 2008.

CAPELA, Paulo Ricardo do Canto. Os mega-eventos esportivos e as políticas públicas de esporte e lazer de resistência. Motrivivência, Ano XVIII, n. 27, pp. 101-116, dez. 2006.

DUNCAN, Sally Anne. Souls Grown Deep and the Cultural Politics of the Atlanta Olympics. Radical History Review, n. 98, Spring 2007, p. 97-118.

EXPO 2010 SHANGHAI CHINA. Shanghai Expo. Disponível em: <http://en.expo2010.cn/>. Acesso em: 25 mai 2010.

FORTUNA, Vania Oliveira. O Rio que nós queremos: o efeito PAN nas representações midiáticas da violência urbana. 111p. Dissertação (Mestrado em 
Ano XXI, n 32/33, junho e dezembro/2009

Comunicação). Universidade do Estado do Rio de Janeiro, Rio de Janeiro, 2009.

GAFFNEY, Cristopher. Mega-events and socio-spatial dynamics in Rio de Janeiro, 1919-2016. Journal of Latin American Geography, v. 9. n. 1, 2010, pp. 7-29.

GIULIANOTTI, Richard; KLAUSER, Francisco. Security Governance and Sport Mega-events: Toward an Interdisciplinary Research Agenda. Journal of Sport and Social Issues, v. 34, n. 1; 2010, pp. 49-61.

GLYNN, Mary Ann. Configuring the Field of Play: How Hosting the Olympic Games Impacts Civic Community. Journal of Management Studies, v. 45, n. 6, pp. 1117-1146, set. 2008.

HILLER, Harry H. Mega-Events, Urban Boosterism and Growth Strategies: An Analysis of the Objectives and Legitimations of the Cape Town 2004 Olympic Bid. International Journal of Urban and Regional Research, v. 24, n. 2, pp. 439-458, jun. 2000.

HORNE, John. The Four 'Knowns' of Sports Mega-Events. Leisure Studies, v. 26, n. 1, pp. 81-96, January 2007.

HORNE, John; MANZENREITER, Wolfram. An introduction to the sociology of sports mega-events. Sociological Review, v. 54, n. 2, pp. 1-24, dez. 2006.
MALFAS, Maximos; THEODORAKI, Eleni; HOULIHAN, Barrie. Impacts of the Olympic Games as mega-events. Municipal Engineer, v. 157, n. 3, pp. 209220, set. 2004.

MASCARENHAS, Gilmar. A cidade e os grandes eventos olímpicos: uma geografia para quem? Lecturas: EF y Deportes, Buenos Aires, Año 10, n. 78, nov. 2004. Disponível em: < http://www.efdeportes. com/efd78/geo.htm $>$. Acesso em: 26 mai. 2010.

PAYNE, Michael. A virada olímpica: como os Jogos Olímpicos se tornaram a marca mais valiosa do mundo. Trad. Dayse Batista. Rio de Janeiro: Casa da Palavra: COB, 2006.

MIYAMOTO, James Shoiti. Os Grandes Eventos Esportivos e a Requalificação Urbana. 313p. Tese (Doutorado em Urbanismo). Universidade Federal do Rio de Janeiro, Rio de Janeiro, 2006.

PILLAY, Udesh; BASS, Orli. Megaevents as a Response to Poverty Reduction: The 2010 FIFA World Cup and its Urban Development Implications. Urban Forum, v. 19, pp. 329-346, 2008.

PRONI, Marcelo Weishaupt; ARAUJO, Lucas Speranza; AMORIM, Ricardo L. C.. Leitura econômica dos Jogos Olímpicos: financiamento, organização e resultados. Rio de Janeiro: IPEA, 2008. 
REIS, Arianne Carvalhedo Dias dos. O impacto dos jogos olímpicos no turismo das cidades sedes. 121p. Dissertação (Mestrado em Educação Física). Universidade Gama Filho, Rio de Janeiro, 2004.

RUBIO, Katia (org). Megaeventos esportivos, legadose responsabilidade social. São Paulo: Casa do Psicólogo, 2007. ROCHE, Maurice. Mega-events and modernity: Olympics and expos in the growth of global culture. New York: Routledge, 2000.

SILVA, Jose da. Gestão da segurança pública em mega eventos esportivos. 272p. Dissertação (Mestrado em Educação Física). Universidade Gama Filho, Rio de Janeiro, 2005.

SILVA, Mauricio Roberto da; PIRES, Giovani De Lorenzi. Do Pan Rio/2007 à Copa 2014 no Brasil. Que Brasil? E para qual Brasil?
Editorial. Motrivivência Ano XVIII, n. 27, pp. 09-17, dez. 2006. VILLANO, Bernardo de Miranda. A Gestão do Conhecimento como elemento de otimização e suporte do processo de gestão de legados de megaeventos esportivos. 95p. Dissertação (Mestrado em Educação Física). Universidade Gama Filho, Rio de Janeiro, 2009.

VRIJALDENHOVEN, Tim van. Reaching Beyond the Gold: the impacts of global events on urban development. Rotterdam: 010 Publishers, 2007.

WHANNEL, Garry. Television and the transformation of sport. The ANNALS of the American Academy of Political and Social Science 2009, v. 625, pp. 205-218.

Recebido: Julho/2010 Aprovado: Agosto/2010 